\title{
PRÁTICA DE EDUCAÇÃO AMBIENTAL: PERCEPÇÃO DE PROFESSORES DO ENSINO FUNDAMENTAL DE ESCOLAS PÚBLICAS MUNICIPAIS DO RIO GRANDE DO SUL
}

\author{
Ana Paula Jaeger ${ }^{1}$ \\ Elisete Maria de Freitas ${ }^{2}$
}

Resumo: A Educação Ambiental (EA) resulta da preocupação com os impactos negativos das ações humanas sobre o ambiente e da necessidade de formar cidadãos ambientalmente mais conscientes. $O$ estudo objetivou conhecer a percepção dos professores de ciências e geografia em relação à EA e como esta vem sendo trabalhada com estudantes dos anos finais do Ensino Fundamental de escolas públicas da região central do Rio Grande do Sul. Foi enviado um convite por e-mail aos professores para a participação na pesquisa contendo o detalhamento dos objetivos da entrevista e o Termo de Consentimento Livre e Esclarecido (TCLE). Mediante confirmação de aceite do TCLE, foi liberado o questionário virtual. Este foi respondido por 10 professores de oito escolas. Constatou-se que a EA é trabalhada de forma superficial e disciplinar, não atendendo a Política Nacional de Educação Ambiental (PNEA). Os professores carecem de uma formação adequada para a prática em EA, pois não possuem um conceito claro do seu significado. As ações adotadas são isoladas, não voltadas para a realidade local e insuficientes para a promoção da mudança nos hábitos dos estudantes. São necessárias ações que promovam mudanças na concepção de EA para que esta seja efetiva na sua prática.

Palavras-chave: Ensino; Conscientização; Meio Ambiente; Percepções.

\footnotetext{
1 Universidade do Vale do Taquari - Univates. E-mail: ana.jaeger@universo.univates.br, Link para o Lattes: http://lattes.cnpq.br/5756476590589626

2 Universidade do Vale do Taquari - Univates. E-mail: elicauf@univates.br, Link para o Lattes: http://lattes.cnpq.br/7345668866571738
} 
Abstract: Environmental Education (EE) results from the concern with the negative impacts of human actions on the environment and the need to form more environmentally conscious citizens. The study aimed to know the perception of science and geography teachers in relation to EE and how it has been worked with students of final years of elementary school in public schools in the central region of Rio Grande do Sul (Brazil). An invitation was sent by email to teachers for survey participation, which contained the interview's objectives detail and the Informed Consent Form (ICF). The virtual questionnaire was released upon ICF acceptance confirmation and it was replied by 10 teachers from eight schools. It was found that EE is worked in a superficial and disciplinary way, not complying with the National Environmental Education Policy. Teachers lack of an adequate training to practice in EE, as they do not have a clear concept of its meaning. The actions taken are isolated without focus on the local reality. Besides, they are insufficient to promote changes in students' habits. In the EE concept, actions that promote changes are necessary for the effectiveness of its practice.

Keywords: Teaching; Awareness; Environment; Perceptions.

\section{Introdução}

O aumento acelerado do desmatamento e das queimadas da floresta Amazônica brasileira nos últimos anos, os incêndios no Pantanal brasileiro em 2020, o rompimento das barragens de Mariana e de Brumadinho em Minas Gerais, Brasil, ocorridas em novembro de 2015 e em janeiro de 2019, respectivamente, o vazamento de óleo no Oceano Atlântico, atingindo a costa brasileira em 2019, constituem eventos recentes que promoveram destruição ambiental e perda significativa da biodiversidade. Estes estão dentre tantos acontecimentos (recentes ou não) que preocupam quem luta pela preservação de todas as formas de vida e pelo equilíbrio ecológico necessário para a boa qualidade de vida da população. Aliado a esses acontecimentos, a aceleração das mudanças climáticas tem agravado o efeito estufa, elevando a temperatura do planeta, promovendo estiagens ou grandes enchentes. Esses acontecimentos impactam e destroem habitats e ecossistemas e afetam a saúde global das pessoas, através do surgimento de novos casos de doenças infecciosas, bacterianas e parasitárias (ONU, 2020), como o que tem ocorrido desde o início de 2020 com a pandemia do coronavírus (COVID-19) exigem uma mudança de postura da população na sua relação com os demais elementos da natureza.

Isso exige que as pessoas sejam mais conscientes das suas atitudes e das consequências de seus hábitos inadequados para a manutenção das condições de vida para todos. Para isso, são necessárias práticas que contribuam para a mudança no modo de pensar e agir das pessoas, passando a aderir e experimentar novas atitudes e comportamentos ambientalmente corretos, se transformando em sujeitos ecológicos (CARVALHO, 2012). Essas 
práticas, segundo o mesmo autor, constituem ações de Educação Ambiental (EA). Como parte de um movimento ecológico, ela "surge da preocupação da sociedade com o futuro da vida e com a qualidade da existência das presentes e futuras gerações".

A preocupação em discutir as questões ambientais do planeta iniciou em 1942 com organizações de eventos internacionais para debater o assunto. Mas foi a partir da Conferência de Estocolmo em 1972 que a prática para educar as pessoas para solucionar os problemas ambientais foi denominada de EA (BEZERRA, 2016). No Brasil, apenas em 27 de abril de 1999, através da Lei № 9.597, foram estabelecidas as Diretrizes Curriculares Nacionais para a Educação Ambiental. O Art. $1^{\circ}$ da referida lei denomina EA como:

Processos por meio dos quais o indivíduo e a coletividade constroem valores sociais, conhecimentos, habilidades, atitudes e competências voltadas para a conservação do meio ambiente, [...] essencial à sadia qualidade de vida e sua sustentabilidade (BRASIL, 1999).

O objetivo da lei é promover a EA em todos os níveis de ensino como uma prática educativa integrada, porém, ela não deve ser implantada como disciplina específica do currículo. Mas, para a sua realização, é necessária a adoção de práticas voltadas para a educação, o que ainda é um grande desafio no âmbito escolar (AGUIAR et al., 2017). Para Reigota (2017), a EA não está relacionada apenas aos aspectos biológicos da vida e não se trata apenas da preservação da fauna e da flora, mas está relacionada diretamente às intervenções que podem fortalecer a relação entre os seres humanos, a natureza e entre nós mesmos. Mas, acima de tudo, a EA busca preparar a sociedade a trilhar um caminho para a possibilidade de estabelecer uma convivência e sobrevivência digna de todos.

Desse modo, a escola foi designada para ser a principal facilitadora do acesso à EA. Assim, cabe ao professor/profissional da educação, sujeito ativo, mediador e transformador da realidade social que tenha os conhecimentos necessários para atuar nesse processo. Porém, ainda existem desafios para a execução da EA nas escolas, como a formação dos professores (independente da disciplina em que atua) e o fato de que, muitas vezes, as escolas não adotam e não priorizam a EA no Projeto Político Pedagógico (PPP) que é a organização do trabalho escolar e o planejamento do que a escola pretende fazer. Outro desafio encontrado é a relação de não se trabalhar a interdisciplinaridade com frequência e o desestímulo que os docentes enfrentam no cotidiano escolar (AGUIAR et al., 2017. VEIGA, 2002).

Segundo Profice (2016), os professores reconhecem que a EA é extremamente necessária, mas poucos se dizem preparados e capazes de serem educadores ambientais. E a nova geração de educadores deve pensar em como levar a temática ambiental para dentro dos conteúdos abordados em 
aula. Em relação aos professores, Profice (2016, p. 35-36) cita um dilema muito importante sobre o educador ambiental no seu encargo de saber e fazer educativo, em que:

Todo educador pode e deve ser ambiental, independente de sua formação ou área de conhecimento [...]. É o educador quem vai buscar aprimorar suas habilidades como educador ambiental a partir de uma reflexão sobre o próprio conhecimento de sua disciplina e de como ele pode ser abordado em EA.

Para Aguiar et al. (2017), trabalhar a EA em sala de aula, deve partir de atividades lúdicas que despertem a curiosidade e a criatividade dos alunos, seja através de experiências e/ou atividades práticas, com diferentes recursos didáticos como músicas, textos, quadrinhos, vídeos, reutilização de materiais, aulas de campo, entre outros que podem ser utilizados nesse processo. Diante disso, questiona-se sobre o preparo dos educadores para atuar na EA e sobre a real concepção que os professores têm sobre sua prática. Esse conhecimento poderá fundamentar ações, tanto de universidades como de secretarias estaduais e municipais de educação, que visem a formação dos atuais e futuros professores para que a EA realmente atenda aos objetivos para o qual foi criada e seja efetiva. Assim, o estudo teve o objetivo de conhecer, relatar e analisar como a EA vem sendo trabalhada nos anos finais do ensino fundamental de escolas públicas de municípios da região central do Rio Grande do Sul.

\section{Material e métodos}

\section{Participantes da pesquisa}

A partir do contato por telefone com escolas públicas da região foi obtido o e-mail de professores das disciplinas de ciências e geografia. A seguir foi enviado um e-mail a esses professores, convidando-os a participar da pesquisa, que só foi realizada mediante a assinatura do Termo de Consentimento Livre e Esclarecido (TCLE). O TCLE revelou o objetivo da pesquisa e esclareceu que a identidade dos participantes e de suas escolas seria mantida em sigilo, seguindo os padrões éticos para pesquisas qualitativas com pessoas. Mediante a assinatura do TCLE, o questionário com 23 perguntas foi liberado a dez professores através da ferramenta Google Forms, disponível no link: $<$ https://docs.google.com/forms/d/e/1FAlpQLSeBJZ1rYZkn9C3UtwLQTnrbVx 4 -Oo37mfcW33xv7y7XmM61w/viewform?usp=sf link>. Foram recebidos 10 questionários de professores do $8^{\circ}$ e $9^{\circ}$ anos do Ensino Fundamental, pertencentes a oito escolas públicas, pertencentes a municípios dos Vales do Taquari e Rio Pardo, na região central do Rio Grande do Sul (RS). Os 
professores, seguindo o proposto no TCLE, foram identificados como Professor "A", Professor "B", ..., Professor "H".

A análise das respostas foi realizada a partir da leitura e tabulação dos dados com transcrição das respostas subjetivas em planilha Excel e ferramenta Google Forms.

\section{Resultados e discussão}

Do total de professores entrevistados, seis eram do sexo feminino e quatro do sexo masculino, sete atuavam como professores de Ciências e três de Geografia. Quando questionados sobre o tempo de formação, 40\% dos professores responderam que concluíram o curso de graduação entre 10 e 20 anos e $30 \%$ há menos de cinco anos (Figura 1). Assim, o tempo médio de atuação em sala de aula, dos professores entrevistados, é de 11,2 anos.

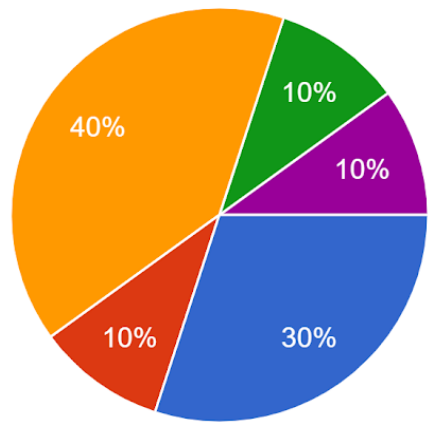

Menos de cinco anos

- De cinco a 10 anos

De 10 a 15 anos

De 15 a 20 anos

De 20 a 25 anos

Figura 1: Percentual de professores de Ciências e Geografia das escolas públicas do Vale do Taquari e Vale do Rio Pardo, RS, por tempo de formação acadêmica.

Fonte: Autoria própria (2020).

Sobre a formação para atuação em EA, $80 \%$ dos professores responderam que tiveram atividades com esse intuito durante o curso de graduação (Figura 2A). Paralelo a isso, apenas $40 \%$ afirmaram ter realizado algum curso complementar relacionado ao tema (Figura $2 \mathrm{C}$ ). Tais informações corroboram com o fato de que $70 \%$ dos entrevistados se consideraram preparados para atuar com EA em suas escolas (Figura 2B). Esse elevado percentual indica que os cursos de graduação e de especialização vem cumprindo com o exigido pela Política Nacional de Educação Ambiental (PNEA), já que esta prevê que os cursos de graduação e de especialização, principalmente nos currículos de formação de professores, trabaIhem conteúdos relacionados à ética ambiental. Assim, "os professores em atividade devem receber formação complementar em suas áreas de atuação", buscando atender aos princípios e objetivos da Política (BRASIL, 1999).

Paralelo a isso, oito entrevistados responderam positivamente quanto à realização de cursos de aperfeiçoamento sobre o tema e justificaram que este é relevante na atualidade e precisam se manter atualizados. Nesse sentido, o 
professor "G" respondeu que realizar cursos "É uma oportunidade de ampliar os conhecimentos sobre o tema e qualificar o meu fazer pedagógico". Já o professor "H" destacou que "a atualização no campo da docência é de extrema importância e se faz necessária, pois o modo de aprender e ensinar vem se modificando constantemente, exigindo que os profissionais estejam qualificados para tal". Conforme cita o professor "F", "o conhecimento nunca é demais; é através de cursos que temos a possibilidade de nos aperfeiçoarmos e nos prepararmos para instruir os estudantes".

O interesse em realizar cursos sobre a temática ambiental reflete sobre o ser humano integrar e ser fundamental nos processos de equilíbrio na relação com a natureza, já que os mesmos podem modificar as formas negativas como essa interação vem acontecendo. Isso é necessário, pois, como ativo nesse processo, o ser humano transforma as condições naturais para permitir a sua própria existência, de acordo com seus interesses e necessidades, o que, consequentemente, traz problemas ambientais (ROBLE, 2009). É através dessa relação do homem com a natureza e a preocupação com as problemáticas ambientais causadas pelo mesmo, que surge a conscientização ambiental como a possibilidade de amenizar os impactos ambientais causados.

Freire (2018) conceitua a conscientização como um processo para o ser humano se redescobrir através de reflexões de sua existência e assim, implicar em ações sobre a realidade para modificá-la, "inserir criticamente os seres humanos na ação transformadora da realidade". Portanto, quando o professor usa a expressão "instruir os estudantes", percebe-se a necessidade de uma mudança em relação à concepção sobre a real prática de EA. Assim, segundo Reigota (2017), "a EA deve ser entendida como educação política, no sentido de que ela reivindica e prepara os cidadãos" a fim de construir uma sociedade ambientalmente correta. Carvalho (1998) afirma que, aos poucos, os educadores estão compreendendo as problemáticas ambientais e vêm se esforçando para construir uma cultura ecologista, preocupada com o ambiente, através da EA. Esta é uma prática a ser construída com a objetividade de mudança em relação aos valores e às posturas educativas.
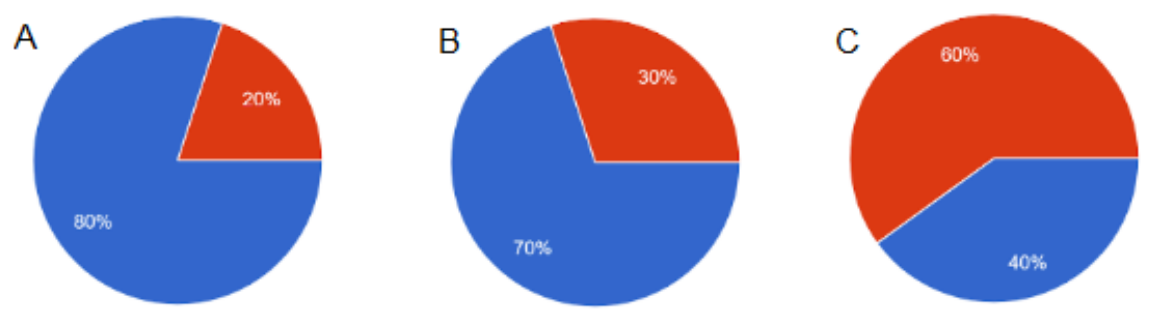

Sim - Não

Figura 2: Percentual de professores das escolas públicas do Vale do Taquari e Vale do Rio Pardo: quanto à formação para atuar em Educação Ambiental (EA) durante o curso de graduação (2A); que se consideraram preparados ou não para atuar com EA em sua escola (2B); que realizaram, ou não, algum curso complementar relacionado à EA (2C).

Fonte: Autoria própria (2020). 
Ao verificar se o PPP das escolas onde os professores entrevistados atuam possui orientação para a EA, apenas cinco professores responderam existir orientações. Nesse sentido, o professor " $G$ " destacou que "não consta nada específico sobre EA, mas em todos os planos de estudos, o tema está presente". O professor "C" afirma que "são abordados temas específicos, tais como água, poluição, gás carbônico, lixo..., mas nada específico sobre EA". Já o professor "H" destacou que são abordados temas como "Sustentabilidade, alimentação saudável e descarte correto de resíduos" enquanto o professor " $F$ " comentou que "A escola possui um projeto de recolhimento e reciclagem de resíduos". Percebe-se, pelas respostas, que os PPP's não definem com clareza como as escolas devem trabalhar EA ou os professores não estão cientes do conteúdo abordado no Plano em relação ao tema. No entanto, as colocações dos professores entrevistados corroboram com os resultados registrados por Miotto, Gonçalves e Dinardi (2018) ao analisarem os PPPs de sete escolas. Os referidos autores comentam que existem registros com a intenção de se trabalhar e fazer projetos sobre EA nos documentos das escolas, porém não se tem uma abordagem detalhada das questões ambientais locais e não há clareza sobre quais ações acerca do assunto a escola pretende desenvolver. Isso também corrobora com Aguiar et al. (2017) e Veiga (2002) quando citam que a EA não é priorizada e adotada no PPP das escolas.

O PPP, construído de forma coletiva com toda a comunidade escolar, define a forma de funcionamento da escola e toda a sua organização curricular. Define também metas e planos sobre o futuro do cidadão que se pretende formar e são abordados os princípios de participação e vivências, sendo indispensável a incorporação da $E A$ em sua estruturação (SILVA; GRZEBIELUKA, 2015). Conforme a Lei $N^{\circ}$ 9795/99, a EA deve ser uma prática educativa integrada e deve estar presente de forma articulada em todos os programas e níveis educativos, porém, é importante enfatizar que ela "não deve ser implantada como disciplina específica no currículo de ensino" (BRASIL,1999).

Abordando ainda o mesmo tema, os entrevistados foram questionados quanto à necessidade de alterações no PPP da escola e, em caso positivo, o que o professor mudaria. As respostas foram de que "A EA ainda está muito associada aos professores de Ciências, como se as outras disciplinas não precisassem se preocupar com o tema" (professor J). O professor "G" comentou que:

Devido à ausência de itens relacionados à EA [...] seria importante tratar de forma mais específica os aspectos relacionados ao meio ambiente, bem como possíveis ações a serem realizadas pela comunidade escolar (PROFESSOR G).

Em relação à existência de projetos ou atividades de $E A$, os professores citaram práticas realizadas como a venda e reciclagem de materiais, coleta da água da chuva, recolhimento de resíduo eletrônico, óleo e pilhas, manutenção 
de horta escolar, reaproveitamento de resíduos orgânicos produzidos pela escola e a realização de trilhas ecológicas. O professor "F" comentou que "nos projetos da Escola, os alunos são livres para escolher os temas e sempre há algum tema relacionado ao meio ambiente, tais como paisagens naturais, extinção de animais, uso de agrotóxicos e outros". Percebe-se também que os professores, em sua maioria, consideram que as práticas de Educação adotadas são adequadas para o atendimento dos objetivos da sua realização. Nesse sentido o professor "A" afirma que, "mesmo sendo ações pontuais, elas conseguem promover a reflexão sobre o tema" enquanto o professor "B" considera que as práticas são um exemplo de boas ações no ambiente de estudo" e que, segundo o professor "F", "estimulam os alunos a terem responsabilidade e saberem da importância que cada um tem com o ambiente". Já o professor "C" comenta que "são boas, mas pelo tamanho da escola, poderiam realizar projetos mais impactantes para o ambiente escolar". $O$ professor " $\mathrm{H}$ " demonstrou maior credibilidade para o atendimento dos objetivos da adoção de práticas de EA em sua escola ao relatar que essas são adequadas porque:

Contribuem com o meio ambiente, com a economia local, aliado à saúde dos seus habitantes. O espaço escolar contribui com a ação e intensifica a aprendizagem dos alunos em relação ao cultivo do próprio alimento, contribuindo para o conhecimento de diferentes formas de manejo e cultivo de outras espécies dos quais os alunos não estão habituados, mas que são alimentos também (PROFESSOR $\mathrm{H}$ ).

Percebe-se certa contrariedade por parte dos professores em suas respostas. Ao mesmo tempo em que julgam importante a realização de atividades de EA em suas escolas, eles não se mostraram tão confiantes no atendimento do propósito da sua realização. É o que também pode ser observado nas respostas dadas para o caso de terem a possibilidade de mudar algo em relação a essas atividades, alguns professores destacaram a necessidade de terem mais tempo para a realização das atividades e de mais envolvimento da comunidade e de órgãos municipais como secretarias de meio ambiente. Também salientaram a necessidade de "Atividades mais coletivas, uma construção com a participação de todos os professores e não só de um professor "apaixonado" pela EA [...], se não for do interesse de todos não funciona $100 \%$ ". O professor " $D$ " enfatizou sobre a necessidade de "refletir a realidade escolar e, a partir desse ponto, pensar em ações, pois projetos impostos aos alunos [..] não funcionam. Ações de professores, a partir do interesse dos alunos, têm mais relevância do que os projetos impostos". Um dos professores aborda e sugere que: 
Para afirmarmos que a EA está sendo trabalhada de maneira plena é preciso ampliar o campo de atuação em relação a tais atividades em nossa escola. Seria necessário focar em projetos e ações mais duradouras. Desta maneira, com projetos interdisciplinares e mais aprofundados, o conhecimento e a vivência de todos sobre 0 tema seriam ampliados (PROFESSOR G).

Os relatos dos professores em relação ao trabalho coletivo e à interdisciplinaridade refletem o que Miranda; Miranda; Ravaglia (2010, p. 12) afirmam: "A educação deve tornar-se assim, uma construção contínua de cada pessoa humana, do seu saber de suas aptidões, de sua capacidade de discernir e agir". E assim deve acontecer com a interdisciplinaridade, um processo de integração entre várias disciplinas e campos de conhecimento, que demanda esforço e uma visão integrada do meio em que vivemos. Trabalhar a interdisciplinaridade não significa que não é possível trabalhar os conteúdos específicos de cada disciplina, mas promover o intercâmbio e o enriquecimento dos temas abordados em sala de aula (MIRANDA; MIRANDA; RAVAGLIA, 2010).

Quanto ao envolvimento dos professores entrevistados em atividades e práticas relacionadas à $\mathrm{EA}$, foi relatado que as atividades dependem da carga horária do professor, em algumas turmas participam mais ativamente, em outras apenas superficialmente, ou ainda, realizam apenas o que thes compete, procurando relacionar as atividades com o conteúdo da disciplina de atuação. O professor "B" comentou que faz o papel de mediador, enquanto o professor "F" afirmou estar sempre atuante e buscando auxiliar os estudantes nas atividades e dúvidas que surgem. O professor "D" afirmou que pouco participa de ações impostas, mas que, de forma inversa, "quando essas surgem a partir do interesse dos estudantes que avaliam a realidade local, participo de forma relevante". Tal posicionamento mostra a ciência do professor quanto à importância de o estudante ser protagonista dos processos de sua aprendizagem.

Por último pedimos aos professores participantes que fizessem uma lista de tudo o que colocariam em um desenho caso tivessem que representar "o que é a natureza" (Tabela 1). Somente dois professores não incluíram o ser humano como integrante da natureza, porém um deles incluiu elementos criados pelo ser humano como parte da natureza. Mesmo sendo apenas dois professores, tal situação é preocupante, pois se o professor não se sente parte integrante da natureza, como vai promover essa percepção entre os estudantes? Krzysczak (2016, p. 12) disse que "ao desenvolvermos trabalhos com pessoas que estão diretamente ligadas ao meio", devemos "atuar como catalisadores de processos educativos que respeitem a pluralidade e a diversidade cultural". Se o professor não se vê como parte do meio ambiente, da natureza, não consegue trabalhar adequadamente esse tema com outras pessoas. Portanto, como citado por Krzysczak (2016), precisamos buscar

Revbea, São Paulo, v.16, № 1: 33-44, 2021.

revista brasileira educação ambiental 
novos meios para manter a ligação entre homem e natureza, da qual ele faz parte, mas ainda não estabelece uma conexão sustentável e equilibrada. Isso porque, segundo o mesmo autor, além de ser uma criatura muito complexa, está constantemente desafiando e alterando o meio ambiente com seus atos. Os efeitos sobre o equilíbrio natural devem ser entendidos e, mesmo com o avanço tecnológico, devemos optar por ações menos ofensivas e mais sustentáveis.

Tabela 1: Elementos indicados pelos professores entrevistados como parte da natureza.

\begin{tabular}{|c|c|c|c|}
\hline Professor & Elementos da natureza & $\begin{array}{l}\text { Elementos } \\
\text { construídos } \\
\text { pelo homem }\end{array}$ & $\begin{array}{c}\text { Incluiu o } \\
\text { ser } \\
\text { humano? }\end{array}$ \\
\hline A & Água, sol, terra, plantas e ser humano. & - & Sim \\
\hline B & Árvores, gramíneas, animais, sol, água e montanhas. & - & Não \\
\hline C & Rios, árvores, pessoas, animais. & & Sim \\
\hline D & $\begin{array}{l}\text { Água, solo e ar (nuvens, talvez); Seres vivos: } \\
\text { animais, entre eles o ser humano; plantas; fungos; } \\
\text { protozoários e monera (dentro de um ser vivo). }\end{array}$ & - & Sim \\
\hline $\mathbf{E}$ & $\begin{array}{c}\text { Solo, plantas, animais, rios, lagos, seres humanos, } \\
\text { seres microscópicos, etc }\end{array}$ & - & Sim \\
\hline $\mathbf{F}$ & $\begin{array}{c}\text { A natureza é tudo o que nos cerca, plantas, todos os } \\
\text { tipos de animais e também de microrganismos que } \\
\text { não vemos, como bactérias, fungos e outros. } \\
\text { Também é os rios, lagos, mares, oceanos, é a chuva, } \\
\text { o vento, o sol. Além de tudo isso, a natureza também } \\
\text { somos nós. }\end{array}$ & - & Sim \\
\hline $\mathbf{G}$ & Água, solo, ar, luz, plantas, animais e pessoas. & - & Sim \\
\hline $\mathbf{H}$ & $\begin{array}{l}\text { Solo, água, céu, nuvens, Sol, pássaros, árvores } \\
\text { frutíferas, pessoas, ar mais puro! }\end{array}$ & $\begin{array}{l}\text { Hortas orgânicas } \\
\text { pela cidade. }\end{array}$ & $\operatorname{Sim}$ \\
\hline $\mathbf{I}$ & $\begin{array}{l}\text { Seres vivos (animais, plantas, fungos) e } \\
\text { componentes abióticos (terra, rochas, água) }\end{array}$ & - & Não \\
\hline $\mathbf{J}$ & $\begin{array}{c}\text { Universo, sol, planeta Terra, água, ar, solo, plantas, } \\
\text { animais e seres humanos. }\end{array}$ & - & $\operatorname{Sim}$ \\
\hline
\end{tabular}

Fonte: Autoria própria (2020). 


\section{Conclusões}

A EA promove a reflexão sobre as ações de cada um no ambiente e a consequente adoção de hábitos e práticas ambientais sadias, sendo a escola um dos ambientes propícios para o desenvolvimento desses hábitos pelas pessoas.

O estudo evidenciou que a EA ainda é trabalhada de forma superficial e disciplinar, não atendendo o que determina a PNEA, já que os PPPs das escolas não detalham como deve ser a sua prática. Além disso, demonstrou que o conceito de EA não está claro para os professores, sendo necessária a realização de cursos de capacitação. O detalhamento das atividades realizadas sugere que estas são ações isoladas, não voltadas para a realidade local e insuficientes para a promoção da mudança nos hábitos dos estudantes. No entanto, essas considerações carecem de observações das práticas realizadas nas escolas e da análise de documentos das escolas, visto que essas atividades não puderam ser realizadas, como proposto inicialmente, em razão da pandemia causada pelo Coronavírus (COVID-19).

\section{Agradecimentos}

Às escolas por fornecerem o contato dos professores e aos professores que aceitaram e participaram da pesquisa.

\section{Referências}

AGUIAR, P. C. B. et al. Da teoria à prática em Educação Ambiental. Revista Gestão \& Sustentabilidade Ambiental, v. 6, n. 2, 2017.

$\begin{array}{lll}\text { BEZERRA, A. A. Fragmentos da história da Educação Ambiental (EA). p.1- } \\ 7, \quad 2016 . & \text { Disponível }\end{array}$ <http://www.cefort.ufam.edu.br/dialogica/files/no3/Vol03-01Fragmentos\%20da\%20historia\%20da\%20educaca0\%20ambiental.pdf>. Acesso em: 13 mar. 2020.

BRASIL. Lei $\mathbf{N}^{\circ} 9795$ de 27 de abril de 1999. Disponível em: https://www.camara.leg.br/proposicoesWeb/prop mostrarintegra;jsessionid=50 EE32BD99AF52EB7D5DB8E7E03AE765.node1?codteor $=634068$ \&filename $=$ L egislacaoCitada+-PL+4692/2009. Acesso em 10 mar. 2020.

CARVALHO, I. C. M. Educação Ambiental: a formação do sujeito ecológico. 6 ed. São Paulo: Cortez, 256 p., 2012.

CARVALHO, I. C. M. Em direção ao mundo da vida: interdisciplinaridade e Educação Ambiental / Conceitos para se fazer Educação Ambiental. Brasília: IPÊ - Instituto de Pesquisas Ecológicas, 1998.

FREIRE, P. Conscientização. Tradução Tiago José Risi Leme. São Paulo: Cortez, 2018. 
KRZYSCZAK, F. R. As diferentes concepções de meio ambiente e suas visões. REI - Revista de Educação do IDEAU, v. 11, n. 23, 2016.

MIOTTO, H. S.; GONÇALVES, R. C.; DINARDI, A. J. A inserção da Educação Ambiental nos documentos que norteiam os diferentes níveis de formação. REMEA - Revista Eletrônica do Mestrado em Educação Ambiental, 2018.

MIRANDA, F. H. F.; MIRANDA, J. A; RAVAGLIA, R. Abordagem Interdisciplinar em Educação Ambiental. Revista Praxis, v. 2, n. 4, ago. 2010.

ONU. Estudo da ONU mostra aceleração das mudanças climáticas em terra, mar e atmosfera. Disponível em: $<$ https://news.un.org/en/story/2020/03/1059061>. Acesso em: 13 mar. 2020.

PROFICE, C. C. Educação Ambiental: dilemas e desafios no cenário acadêmico brasileiro. REDE - Revista Eletrônica do PRODEMA, v. 10, n. 1, 2016.

REIGOTA, M. O que é Educação Ambiental. 2. ed. São Paulo: Brasiliense, 2017. E-book. Disponível em: <https://books.google.com.br/books?hl=ptBR\& $r=\& i d=g m g v D w A A Q B A J \& o i=f n d \& p g=P T 2 \& d q=e d u c a \% C 3 \% A 7 \% C 3 \% A 30$ + ambiental\&ots $=4$ gtAah787g\&sig=iyNb-

6rKR2zcHHEczTEfPvqu9e0\#v=onepage\&q=educa\%C3\%A7\%C3\%A30\%20am biental\&f=false. Acesso em: 02 jan. 2020>.

ROBLE, O. Conhecimento do Homem, da Natureza e da Sociedade. Curitiba: IESDE Brasil S. A., 2009.

SILVA, J. A.; GRZEBIELUKA, D. Educação Ambiental na escola: do Projeto Político Pedagógico a prática docente. Revista Monografias Ambientais Santa Maria, v. 14, n. 3, 2015.

VEIGA, I. P. A. Projeto político-pedagógico da escola: uma construção coletiva. In: VEIGA, I. P. A. et al. (Org.). Projeto político-pedagógico da escola: uma construção possível. Campinas: Papirus, 2002. 